Is Psychological Treatment Equally Effective for Intimate Partner Violence Perpetrators with and without Childhood Family Violence?

Javier Fernández-Montalvo ${ }^{1,2}$, José A. Echauri ${ }^{3}$, Sandra Siria ${ }^{1}$, José J. López-Goñi ${ }^{1,2}$, Juana M. Azcárate ${ }^{3}$, and María Martínez ${ }^{3}$

${ }^{1}$ Departament of Health Sciences, Universidad Pública de Navarra, Pamplona. Spain. ${ }^{2}$ Instituto de Investigación Sanitaria de Navarra (IdiSNA), Pamplona. Navarra. Spain. ${ }^{3}$ Psimae. Instituto de Psicología Jurídica y Forense, Pamplona, Navarra, Spain.

Corresponding Author: Javier Fernández-Montalvo. Department of Health Sciences. Universidad Pública de Navarra, Campus de Arrosadía, 31006 Pamplona, Spain. Email: fernandez.montalvo@unavarra.es

This is the peer reviewed version of the following article: Fernández-Montalvo, J., Echauri, J.A., Siria, S., López-Goñi, J.J., Azcárate, J.M. and Martínez, M. (2020), Is psychological treatment equally effective for intimate partner violence perpetrators with and without childhood family violence? Leg Crim Psychol. , which has been published in final form at https://doi.org/10.1111/lerp.12187. This article may be used for non-commercial purposes in accordance with Wiley Terms and Conditions for Use of Self-Archived Versions. 


\begin{abstract}
Purpose: This study assessed the differential long-term effectiveness of a standard treatment programme for intimate partner violence male perpetrators (IPV-P), depending on the presence of childhood family violence (CFV). Methods: A sample of 1008 male IPV-P were included in the study. Comparisons between men with CFV ( $n=$ 339) and without CFV $(n=669)$ on socio-demographic characteristics and psychopathological variables were carried out at pre-treatment. The differential effectiveness of the treatment was assessed at post-treatment and at 1-year follow-up. Results: The pre-treatment assessment showed that IPV-P with CFV had a lower level of education, higher rates of previous psychiatric history and more voluntary access to the treatment. Moreover, they began the treatment programme with more psychopathological symptoms, assessed by the SCL-90-R and STAXI-2. Regarding treatment results, the attrition rates did not reach significant differences between groups. The repeated-measures ANOVA evidenced statistically significant improvement in psychopathological symptoms on most of the variables for both groups. However,


comparisons between groups on psychopathological symptoms showed that IPV-P with CFV were affected to a significantly higher degree on many variables at post-treatment and follow-up, although no differences were found in the global rates of treatment outcomes. Conclusions: This investigation highlights the heterogeneity of IPV-P and the differential progression along the treatment programmes according to the presence of CFV.

Keywords: intimate partner violence, perpetrators, childhood family violence, assessment, treatment 


\section{Is Psychological Treatment Equally Effective for Intimate Partner Violence Perpetrators with and without Childhood Family Violence?}

Intimate partner violence (IPV) perpetration has received much attention in the literature due to the relevance of its consequences. One of the most critical challenges for practitioners working with IPV male perpetrators (IPV-P) is to reduce the risk of recidivism. Researchers have made an effort to assess the effectiveness of different treatment programmes, obtaining inconsistent findings and small effect sizes (Carbajosa et al., 2017; Karakurt et al., 2019; Saunders, 2008). One possible explanation for the limited success of the programmes may be the diversity of designs used to evaluate the effectiveness of the treatments (Saunders, 2008). On the other hand, treatment programmes do not usually take into account the heterogeneity of IPV-P, applying a standardized treatment to all of them and leaving unattended differential needs (Carbajosa et al., 2017; Cunha \& Goncalves, 2013). What seems to be relatively stable across investigations is that the risk of recidivism is higher for IPV-P who do not complete any treatment than for those who had been engaged in an intervention (Lauch et al., 2017; Lila et al., 2019; Ruddle et al., 2017).

Thus, a relevant issue to tackle is the development of specific treatment programmes according to the different criminogenic needs and risk factors of IPV-P (Cunha \& Goncalves, 2013; Lauch et al., 2017). In this sense, matching the offender type with a tailored intervention could improve treatment effectiveness (Carbajosa et al., 2017; Saunders, 2008). The existing IPV-P typologies might lead to reaching this target through the identification of specific risk factors, individual processes to perpetrate IPV, and different levels of recidivism risk (Voith, Topitzes, et al., 2020). These typologies have been established according to drug or alcohol misuse (Vitoria-Estruch et al., 2018), 
personality characteristics (Cunha \& Goncalves, 2013; White \& Gondolf, 2000), the extent of violence inside and/or outside the family (Holtzworth-Munroe \& Stuart, 1994; Waltz et al., 2000), previous criminal records (Herrero et al., 2016; Teva et al., 2020), or childhood family violence (CFV) (Lee et al., 2013; Mbilinyi et al., 2012; Murrell et al., 2007).

One of the most important individual risk factors for IPV-P is the presence of CFV (Davis et al., 2018; Fulu et al., 2017; Godbout et al., 2009), although not all of them have been exposed to it (Wareham et al., 2009). These negative interpersonal life events may have an impact on the capacity to assume appropriate adult roles in relationships (Godbout et al., 2009). Nevertheless, as a critical risk factor that can differentiate this population in terms of personality profiles (Lee et al., 2013), the frequency of IPV (Mbilinyi et al., 2012; Murrell et al., 2007), the type and severity of IPV (Lee et al., 2013; Murrell et al., 2007), or criminal versatility (Teva et al., 2020), it has not been examined in-depth in the research. Therefore, CFV could be a crucial variable in the development of these typologies and, consequently, in the implementation of tailored treatment interventions.

CFV among IPV-P has been associated with long-term consequences, such as mental health problems, developmental delays in cognitive, behavioural and emotional processing and regulation, ineffective social processing, poor self-regulation, greater acceptability and normalization of violence, a tendency towards aggression, and attachment problems (Lila et al., 2019; Ruddle et al., 2017; Swopes et al., 2013). Moreover, previous studies have demonstrated that IPV-P reporting CFV have a more severe profile and more associated psychopathological symptoms than those who have not been exposed to family violence (Fernández-Montalvo et al., 2020; Wareham et al., 
2009). Thus, treatments should consider CFV in terms of recidivism prevention. Most of the studies carried out to date have focused on the relationship between CFV and treatment attrition. However, no previous research assessing the effectiveness of tailored treatment programmes for IPV-P with CFV has been conducted.

Studies focused on the relationship between CFV and completion/dropout rates show inconsistent results (Daly \& Pelowski, 2000). While some investigations have demonstrated that CFV is a predictor of treatment completion (Chang \& Saunders, 2002; Fernández-Montalvo et al., 2015), others have identified CFV as a dropout variable after the initiation of treatment (Cadsky et al., 1996; Lauch et al., 2017). Additionally, other studies have shown a non-significant association (Daly \& Pelowski, 2000; Jewell \& Wormith, 2010). The one-size-fits-all treatment designs in which IPV-P are usually allocated and the lack of specific intervention programmes focused on the criminogenic needs and capacities of the offenders responding to the Risk-NeedResponsivity model (R-N-R) (Andrews \& Bonta, 2017) have been proposed as a possible explanation for these inconsistent results (Crane \& Easton, 2017).

There is a need for updated and enhanced treatment models on the basis of the individual needs of the participants (Crane \& Easton, 2017; Karakurt et al., 2019). The meta-analysis conducted by Karakurt et al. (2019) about the effectiveness of different intervention programs for IPV-P, found that intervention programmes that incorporated the trauma perspective yielded better results in reducing violence. According to the results obtained, these authors state that treating the underlying problems of IPV-P is vital to treatment success. Therefore, effective interventions should include traumainformed practice (Schauss et al., 2019) because the consideration of CFV for treatment seems to be a promising starting point for future intervention models. 
No previous studies have been found comparing treatment effectiveness taking into consideration the presence of CFV among IPV-P. Therefore, the main goal of this study was to assess the differential long-term effectiveness of a standard treatment programme for IPV-P depending on the presence of CFV. Specifically, participants with and without CFV were compared at pre-treatment (socio-demographic characteristics and psychopathological symptoms), post-treatment, and 1-year follow-up. The main hypothesis of this study was that IPV-P without CFV would present with a lower recidivism rate and lower levels of psychopathological symptoms associated after receiving the treatment programme. This study will allow to test whether a standard treatment programme is equally effective for these two groups of IPV-P.

\section{Methods}

\section{Participants}

The initial sample in this study consisted of 1300 male IPV-P who were in a specialized treatment programme after committing an offence of gender violence against their female partner. This programme is developed by PSIMAE (Institute of Judicial and Forensic Psychology), is directed by the Social Service of Justice of the Government of Navarre (Spain), and provides treatment for all IPV-P in Navarre. All participants were assessed from January 2005 to December 2019. None of them received a monetary compensation for participating in the study.

The sample inclusion criteria were (a) being older than 18 years of age; (b) having been involved in violence against a female partner; (c) not suffering from any serious mental disorder after being assessed by a clinical psychologist; (d) having knowledge of the Spanish language; and (e) signing the informed consent to participate in the study after having been properly informed of its characteristics. 
Following the abovementioned admission criteria, 253 men $(19.5 \%)$ were excluded from the study, and $39(3 \%)$ refused to participate. Therefore, $1008(77.5 \%$ of the initial sample) subjects were studied (Figure 1).

\section{PLACE FIGURE 1 HERE}

The mean age of the sample was 37.4 years $(S D=10.43)$. Nearly half of the sample (49.6\%) was Spanish, and the rest of the participants were from other countries (50.4\%). Moreover, 339 (33.6\%) had a history of CFV, and $669(66.4 \%)$ had not. Most of the participants were court-referred to the treatment programme $(n=701,69.5 \%)$, others were imprisoned ( $n=227,22.5 \%)$, and the remaining subjects $(n=80,7.9 \%)$ sought treatment voluntarily. The rationale of placing a subject in a court-referred treatment versus an imprisonment treatment is mainly related to the severity of the offence against the partner. Spanish legislation allows judges to impose a suspended sentence if three conditions are met: the person is a first-time offender, the sentence imposed does not exceed two years of imprisonment, and the offender agrees to participate in a specialized treatment programme.

\section{Assessment Measures}

The General Structured Interview of Batterer Men (Echeburúa \& FernándezMontalvo, 1998) consists of five sections that collect data on the respondents' demographic characteristics, potential labour problems, child and adolescent development, potential problems of IPV in previous relationships, the current situation with their partners, health status, criminal records, and social relations. It also explores psychopathological variables that are usually related to gender violence perpetrators (mainly jealousy and abuse of alcohol). This interview was used to identify the selfreported presence and characteristics of CFV (physical, psychological, and/or sexual) 
among the participants in the sample, taking into account whether they had directly suffered or witnessed the abuse.

The Symptom Checklist-90-Revised (SCL-90-R) (Derogatis, 1992; González de Rivera, 2002) is a self-administered general psychopathological assessment questionnaire. It consists of 90 questions that are answered on a 5-point Likert-type scale, ranging from 0 (none) to 4 (very much). The questionnaire aims to assess the respondent's psychiatric symptoms. The SCL-90-R has been shown to be sensitive to therapeutic change and may therefore be used for either single or repeated assessments. The SCL-90-R measures the following nine areas of primary symptoms: somatization, obsessive-compulsive behaviours, interpersonal sensitivity, depression, anxiety, hostility, phobic anxiety, paranoid ideation, and psychoticism. It also provides three indexes that reflect the subject's overall level of severity: the Global Severity Index (GSI), the Positive Symptom Distress Index (PSDI), and the Positive Symptom Total (PST). The internal consistency for the Spanish version ranges from .70 to .90 .

The State-Trait Anger Expression Inventory (STAXI-2) (Miguel-Tobal et al., 2001; Spielberger, 1999) consists of 15 items related to state-anger (the intensity of the emotion of anger in a specific situation) and 10 additional items related to trait-anger (the individual disposition to experience anger habitually). The range of scores is from 15 to 60 on the state-anger scale and from 10 to 40 on the trait-anger scale. The higher the score is, the higher the level of anger. The STAXI-2 also has a third subscale of 24 items connected with the form of expressing anger (anger expression-out, anger expression-in, and anger control). The internal consistency for the Spanish version ranges from .82 to .89 .

\section{Treatment Programme}


The intervention is a broad treatment programme that is based on cognitive behavioural therapy. It is composed of 20 one-hour individual sessions delivered once a week. The programme includes the modification of cognitive distortions and behavioural deficits related to IPV. There is a unique general protocol, which has been applied to all of the participants during the research time. However, depending on the clinical judgement, the therapists can adapt the length or the techniques used to the specific current needs of each participant. A clinical psychologist of the programme centre conducted the treatment sessions.

In the first part of the intervention (sessions 1-3), motivational aspects, such as the acceptance of responsibility for the IPV and motivation for therapy, are taken into account. The second part (sessions 4-15) includes the treatment of psychopathological symptoms that are usually associated with violent men. This part focuses on empathy and skills training, anger management, and the modification of cognitive distortions related to IPV. Finally, the treatment programme includes a specific intervention in relapse prevention (sessions 16-20) by identifying high-risk situations for violent behaviour and teaching IPV-P adequate coping strategies that provide an alternative response to violence.

The structure is based on the treatment programme developed by Echeburúa and Fernández-Montalvo (1998) for IPV-P. It was later extended and adapted for prisonbased treatment (identifying reference removed) and court-referred treatment programmes (identifying reference removed) of IPV-P, as well as for the immigrant population (identifying reference removed) and patients with substance use disorders (identifying reference removed).

\section{Procedure}

Fernández-Montalvo, J., Echauri, J.A., Siria, S., López-Goñi, J.J., Azcárate, J.M. y Martínez, M. (in press). Is Psychological Treatment Equally Effective for Intimate Partner Violence Perpetrators with and without Childhood Family Violence? Legal and Criminological

Psychology. https://doi.org/10.1111//crp.12187 
The protocol for this study was approved by the ethics committee of the XXX (identifying information removed) (code XXX).

After the clinical sample was selected based on the previously described criteria, the initial assessment of the sample was carried out in two sessions. The sessions took place once a week for two weeks, and the time interval between the sessions was the same for each participant. The data related to sociodemographic characteristics and violence variables were collected in the first session. In the second session, the presence of psychopathological symptoms was assessed using the SCL-90-R and the STAXI-2.

Once the total sample was assessed, participants were divided into two groups depending on the presence of CFV to evaluate the differential effectiveness of the treatment programme.

The next assessments were carried out after the treatment ended and after a oneyear follow-up. A clinical psychologist for the programme conducted all the individual assessment and treatment sessions.

In this research, three levels of therapeutic change were taken into account after the follow-up period: success, improvement, and failure. "Treatment success" was defined throughout two criteria: (a) the complete disappearance of the episodes of IPV during the one-year follow-up period; and (b) a decrease in the associated psychopathological symptoms assessed by the SCL-90-R and STAXI-2 to the standard criteria of "normality" specified in both instruments for normative samples and a clear change in the variables related to empathy, distorted thinking, resistance to change, and coping strategies according to the therapeutic team's evaluation. In those cases in which at the end of the treatment programme the participant was still in prison and did not have opportunity to engage in episodes of IPV, fulfilment of criterion (b) was 
considered as "treatment success". "Treatment improvement" was understood as the complete disappearance of the episodes of IPV but without any clear change in the associated psychopathological symptoms or in the variables mentioned above. Finally, "treatment failure" was primarily based on the repetition of episodes of IPV or on a negative professional evaluation related to a poor treatment response and to the patient's resistance to change.

The recidivism (presence or disappearance of violent episodes) was assessed using both criminal justice databases of IPV charges and participants' self-report of repeated offenses.

\section{Design}

A longitudinal naturalistic comparison of treatment success for two groups of IPV perpetrators (with and without CFV) was carried out. Repeated measures at preintervention, post-intervention and 1-year follow-up were used to analyse the programme outcomes.

\section{Data Analysis}

First, the distribution of missing data was studied, and no significant differences were found between subjects with and without available data on each of the variables studied during pre-treatment. Therefore, the pairwise deletion method was selected; this method involves analysing the available cases for each variable. Descriptive analyses were performed for all variables. In the bivariate analyses between IPV-P with and without CFV, a $\chi^{2}$ or Student's $t$-test for independent samples was used, depending on the nature of the variables analysed. Effect sizes (Cohen's $d$ ) were provided as follows: $d=0.20$ (small effect size), $d=0.50$ (medium effect size), and $d=0.80$ (large effect size). A repeated-measures multivariate analysis of variance (MANOVA) was carried 
out to evaluate the results of the intervention (pre-treatment, post-treatment and followup) and the interaction with CFV. This MANOVA was conducted with the GSI of the SCL-90-R and with the Index of Anger Expression of the STAXI. Moreover, repeated measures ANOVA analyses with Bonferroni adjustment were carried out to evaluate changes in the continuous variables. A difference of $p<.05$ was considered significant. All statistical analyses were performed using SPSS (version 25.0) software.

\title{
Results
}

\section{Comparisons of Sociodemographic Variables and Treatment Programme Access}

The results of the comparisons of sociodemographic variables are shown in Table 1. Statistically significant differences were found for some variables. IPV-P with CFV presented a longer relationship with the victim, a lower level of education, and a higher prevalence of previous psychiatric history, and they had more children together with the victim than did those without CFV. Moreover, the rate of voluntary access to the treatment programme was significantly higher for IPV-P with CFV.

\section{PLACE TABLE 1 HERE}

\section{Comparisons of Treatment Outcomes}

The rate of retention in this study was $79.4 \%$, without statistically significant differences between participants with and without CFV (Table 2). Regarding treatment results, both groups showed similar rates of treatment success, improvement, and failure. No significant differences were found among IPV-P with CFV between those who directly suffered and those who witnessed maltreatment $\left(\chi^{2}=0.71 ; p=.702\right)$.

\author{
PLACE TABLE 2 HERE
}

\section{Comparisons of Scores of Psychopathological Variables along the Treatment}


Comparisons between groups on the SCL-90-R and the STAXI-2 scores at the three assessment points (pre-treatment, post-treatment, and one-year follow-up) are shown in Table 3. IPV-P with CFV were affected by psychopathological symptoms to a significantly higher degree than were those without CFV at the initial assessment. In the post-treatment assessment, the scores of both groups were lower. Even so, participants with CFV still had significantly higher rates on most of the variables. At the end of the follow-up period, IPV-P with CFV maintained significantly higher scores than did those without CFV on four variables: PST, interpersonal sensitivity, paranoid ideation, and psychoticism.

\section{PLACE TABLE 3 HERE}

\section{Multivariate Analysis for Interaction Between Treatment Results and CFV}

Before the MANOVA was performed, a Box's $M$ test of equality of covariance matrices was performed, and it was significant (Box's $M=71.11 ; F=3.35 ; d f 1=21 ; d f$ $2=1,005,171.985 ; p<.001)$. Thus, the Greenhouse-Geisser correction was used. Moreover, Bonferroni-type adjustments for univariate F-tests were carried out to prevent an inflated Type I error rate. In addition, Levene's test of equality of error variances was calculated for the GSI $(p=.057)$ and Index of Anger Expression $(p=$ .472), without significant results.

The repeated-measures MANOVA for the intervention (pre-treatment, posttreatment, and follow-up) showed a significant Wilks' Lambda $(F=68.13 ; d f=4 ; p<$ $.001)$. No significant Wilks' lambda was found for the CFV x time interaction $(F=2.92$; $d f=4 ; p=.20)$ 
When each measure was examined separately, statistically significant improvements between pre-treatment and post-treatment were found (Table 4). These results were maintained in the follow-up assessment.

\section{PLACE TABLE 4 HERE}

\section{Discussion}

The current research was conducted to assess the differential long-term outcomes of a standard treatment programme for IPV-P with and without CFV. This differential evaluation is needed for two main reasons: first, exposure to childhood trauma and family violence are robust risk factors for the development of IPV and psychopathological disorders (Elklit et al., 2018; Reitzel-Jaffe \& Wolfe, 2001); and second, IPV-P with CFV present with more severe psychopathological symptoms when they attend treatment programmes (Fernández-Montalvo et al., 2020; Lee et al., 2013; Mbilinyi et al., 2012). The principal hypothesis of the study was not supported because no statistically significant differences were found between groups in terms of treatment failure, improvement, or success.

The retention rate in this study is high, as almost $80 \%$ of all the participants who began the treatment finished the intervention. As some researchers have evidenced before, the CFV here is not associated with treatment adherence (Daly \& Pelowski, 2000; Jewell \& Wormith, 2010). Moreover, the dropout rates in this sample are lower than those found in previous studies, which have dropout rates ranging between $50 \%$ and 75\% (Babcock et al., 2004; Feder \& Wilson, 2005; Stover et al., 2009). This discrepancy could be related to the fact that most of the participants in this study were court-referred to the programme, having a suspended sentence that depended on the treatment progress. As previous studies on court-referred treatment programmes have 
shown, the retention rate in these cases is usually high (Fernández-Montalvo et al., 2015).

The findings revealed that IPV-P with CFV had more severe psychopathological profiles at the beginning of the treatment, which is consistent with the results of previous studies (Fernández-Montalvo et al., 2020; Lee et al., 2013; Mbilinyi et al., 2012). At the one-year follow-up, all participants in the sample scored significantly lower on all psychopathological symptoms, and the rates of success, improvement, and failure did not show significant differences between groups. This result could lead to the conclusion that the standardized treatment is equally effective for both groups. However, it should be taken into account that this treatment is delivered individually. Consequently, all patients have received a tailored intervention considering the individual progression and specific needs. This could partially explain the lack of differences between groups. In any case, what appears remarkable at the follow-up assessment is that IPV-P with CFV still scored significantly higher on relevant variables such as PST, interpersonal sensitivity, paranoid ideation, and psychoticism. Some authors have also found that IPV-P with CFV have worst outcomes (Lee et al., 2013). Future research should focus on addressing the biopsychosocial consequences of child maltreatment and trauma exposure (Schauss et al., 2019), as well as other factors that could contribute to the worst treatment results. Perhaps, a more individualized treatment that addresses the specific needs of this population could lead to better results.

$\mathrm{CFV}$ is not the only unique risk factor that should be addressed in individualized treatments. There are several dynamic risk and protective factors that should be included in intervention programmes, but the identification of the earliest risk markers and unresolved traumas is a critical preliminary step (Rosenbaum \& Leisring, 2003; 
Voith, Logan-Greene, et al., 2020). Lauch et al. (2017) stated that although results regarding the relationship between CFV and treatment outcomes are inconclusive, CFV is an important factor to identify treatment needs and to design the intervention. In this sense, Karakurt et al. (2019) concluded that treatments that include a trauma component yielded improved results. As different types of IPV-P can respond in varied ways to treatments and can present different levels of recidivism (Carbajosa et al., 2017), following models such as the R-N-R framework will individualize professional responses (Andrews \& Bonta, 2017). Future tailored interventions should also incorporate motivational interviewing techniques to ensure that participants have the initial internal motivation to change abusive behaviour (Crane \& Easton, 2017), as well as to engage participants in treatment over time (Karakurt et al., 2019).

This study has some limitations that must be considered. First, the majority of IPV-P in this sample agreed to participate in the treatment in exchange for the suspension of a harsher sentence. It is important to take into account this circumstance in terms of treatment attrition and treatment outcomes. Second, the interpretation of findings is based on those who completed the treatment. Consequently, this may indicate that the treatment programme works for a presumably more motivated subset of offenders (Feder \& Wilson, 2005). Third, this study used retrospective self-reports to assess CFV. The difficulty for some men to accurately remember all violent situations, or their tendency to minimize them, could have led to underreported rates of CFV and biased the results. Moreover, it was not possible to analyse the types of CFV suffered and/or witnessed by the sample (e.g., psychological, physical and/or sexual). Future studies should consider the specific characteristics of the CFV to assess the differential mediation effects on IPV perpetration. Finally, the type of IPV perpetrated (physical, 
psychological and/or sexual) was not assessed in the sample. It would be interesting to establish if there is a link among the type of CFV suffered/witnessed, the type of IPV perpetrated, and the psychological profiles of IPV-P.

This investigation contributes to evidence of the heterogeneity of IPV-P. The results showed that those with CFV presented with a more severe psychopathological profile at the beginning of the treatment. Although no statistically significant differences between groups in treatment progression were found, IPV-P with CFV still presented with more psychopathological symptoms at the end of the programme. Some authors have found that without attention to childhood victimization, interventions may be less effective for IPV-P with CFV (Lee et al., 2013). Therefore, psychological assessments and intervention programmes should include a childhood trauma perspective and address its long-term consequences from an integrated framework. It is clearly necessary to develop research attending to treatment efficacy for different types of IPV-P and to use its results to optimize treatments to reduce IPV perpetration. 


\section{References}

Andrews, D. A., \& Bonta, J. (2017). The psychology of criminal conduct (6th Edition). Routledge.

Babcock, J. C., Green, C. E., \& Robie, C. (2004). Does batterers' treatment work? A meta-analytic review of domestic violence treatment. Clinical Psychology Review, 23(8), 1023-1053. https://doi.org/10.1016/j.cpr.2002.07.001

Cadsky, O., Hanson, R. K., Crawford, M., \& Lalonde, C. (1996). Attrition from a male batterer treatment program: Client-treatment congruence and lifestyle instability. Violence and victims, 11(1), 51-64. https://doi.org/10.1891/0886-6708.11.1.51

Carbajosa, P., Catala-Minana, A., Lila, M., \& Gracia, E. (2017). Differences in treatment adherence, program completion, and recidivism among batterer subtypes. European Journal of Psychology Applied to Legal Context, 9(2), 93101. https://doi.org/10.1016/j.ejpal.2017.04.001

Chang, H., \& Saunders, D. G. (2002). Predictors of attrition in two types of group programs for men who batter. Journal of Family Violence, 17(3), 273-292. https://doi.org/10.1023/A:1016057328929

Crane, C. A., \& Easton, C. J. (2017). Integrated treatment options for male perpetrators of intimate partner violence. Drug and Alcohol Review, 36(1), 24-33. https://doi.org/10.1111/dar.12496

Cunha, O., \& Goncalves, R. A. (2013). Intimate partner violence offenders: Generating a data-based typology of batterers and implications for treatment. European Journal of Psychology Applied to Legal Context, 5(2), 131-139. https://doi.org/10.5093/ejpalc2013a2

Daly, J. E., \& Pelowski, S. (2000). Predictors of dropout among men who batter: A review of studies with implications for research and practice. Violence and victims, 15(2), 137-160. https://doi.org/10.1891/0886-6708.15.2.137

Davis, K. C., Masters, N. T., Casey, E., Kajumulo, K. F., Norris, J., \& George, W. H. (2018). How childhood maltreatment profiles of male victims predict adult perpetration and psychosocial functioning. Journal of Interpersonal Violence, 33(6), 915-937. https://doi.org/10.1177/0886260515613345

Derogatis, L. R. (1992). The SCL-90-R. Clinical Psychometric Research.

Echeburúa, E., \& Fernández-Montalvo, J. (1998). Instrumentos de evaluación de los maltratadores. In E. Echeburúa \& P. Corral (Eds.), Manual de violencia familiar (pp. 91-129). Siglo XXI.

Elklit, A., Murphy, S., Jacobsen, C., \& Jensen, M. K. (2018). Clinical and personality disorders in a Danish treatment-seeking sample of intimate partner violence perpetrators. International Journal of Offender Therapy and Comparative Criminology, 62(11), 3322-3336. https://doi.org/10.1177/0306624x17741603

Feder, L., \& Wilson, D. B. (2005). A meta-analytic review of court-mandated batterer intervention programs: Can courts affect abusers' behavior? Journal of Experimental Criminology, 1, 239-262. https://doi.org/10.1007/s11292-005$\underline{1179-0}$

Fernández-Montalvo, J., Echauri, J. A., Azcárate, J. M., Martínez, M., Siria, S., \& López-Goñi, J. J. (2020). What differentiates batterer men with and without histories of childhood family violence? Journal of Interpersonal Violence, 1-20. https://doi.org/10.1177/0886260520958648 
Fernández-Montalvo, J., Echauri, J. A., Martínez, M., Azcárate, J. M., \& López-Goñi, J. J. (2015). Impact of a court-referred psychological treatment program for intimate partner batterer men with suspended sentences. Violence and Victims, 30(1), 3-15. https://doi.org/10.1891/0886-6708.vv-d-13-00026

Fulu, E., Miedema, S., Roselli, T., McCook, S., Chan, K. L., Haardorfer, R., \& Jewkes, R. (2017). Pathways between childhood trauma, intimate partner violence, and harsh parenting: Findings from the UN multi-country study on men and violence in Asia and the Pacific. Lancet Global Health, 5(5), E512-E522. https://doi.org/10.1016/s2214-109x(17)30103-1

Godbout, N., Dutton, D. G., Lussier, Y., \& Sabourin, S. (2009). Early exposure to violence, domestic violence, attachment representations, and marital adjustment. Personal Relationships, 16(3), 365-384. https://doi.org/10.1111/j.14756811.2009.01228.x

González de Rivera, J. L. (2002). SCL-90-R. Cuestionario de 90 síntomas. TEA Ediciones.

Herrero, J., Torres, A., Fernandez-Suarez, A., \& Rodriguez-Diaz, F. J. (2016). Generalists versus specialists: Toward a typology of batterers in prison. European Journal of Psychology Applied to Legal Context, 8(1), 19-26. https://doi.org/10.1016/j.ejpal.2015.09.002

Holtzworth-Munroe, A., \& Stuart, G. L. (1994). Typologies of male batterers: Three subtypes and the differences among them. Psychological Bulletin, 116(3), 476497. https://doi.org/10.1037/0033-2909.116.3.476

Jewell, L. M., \& Wormith, J. S. (2010). Variables associated with attrittion from domestic violence treatment programs targeting male batterers: A meta-analysis. Criminal Justice and Behavior, 37(10), 1086-1113. https://doi.org/10.1177/0093854810376815

Karakurt, G., Koc, E., Cetinsaya, E. E., Ayluctarhan, Z., \& Bolen, S. (2019). Metaanalysis and systematic review for the treatment of perpetrators of intimate partner violence. Neuroscience and Biobehavioral Reviews, 105, 220-230. https://doi.org/10.1016/j.neubiorev.2019.08.006

Lauch, K. M., Hart, K. J., \& Bresler, S. (2017). Predictors of treatment completion and recidivism among intimate partner violence offenders. Journal of Aggression Maltreatment \& Trauma, 26(5), 543-557. https://doi.org/10.1080/10926771.2017.1299824

Lee, R. D., Walters, M. L., Hall, J. E., \& Basile, K. C. (2013). Behavioral and attitudinal factors differentiating male intimate partner violence perpetrators with and without a history of childhood family violence. Journal of Family Violence, 28(1), 85-94. https://doi.org/10.1007/s10896-012-9475-8

Lila, M., Martin-Fernandez, M., Gracia, E., Lopez-Ossorio, J. J., \& Gonzalez, J. L. (2019). Identifying key predictors of recidivism among offenders attending a batterer intervention program: A survival analysis. Psychosocial Intervention, 28(3), 157-167. https://doi.org/10.5093/pi2019a19

Mbilinyi, L. F., Logan-Greene, P. B., Neighbors, C., Walker, D. D., Roffman, R. A., \& Zegree, J. (2012). Childhood domestic violence exposure among a community sample of adult perpetrators: What mediates the connection? Journal of Aggression Maltreatment \& Trauma, 21(2), 171-187. https://doi.org/10.1080/10926771.2012.639203 
Miguel-Tobal, J. J., Casado, M. I., Cano-Vindel, A., \& Spielberger, C. D. (2001). Versión española del STAXI-2. TEA Ediciones.

Murrell, A. R., Christoff, K. A., \& Henning, K. R. (2007). Characteristics of domestic violence offenders: Associations with childhood exposure to violence. Journal of Family Violence, 22(7), 523-532. https://doi.org/10.1007/s10896-007-9100-4

Reitzel-Jaffe, D., \& Wolfe, D. A. (2001). Predictors of relationship abuse among young men. Journal of Interpersonal Violence, 16(2), 99-115. https://doi.org/10.1177/088626001016002001

Rosenbaum, A., \& Leisring, P. A. (2003). Beyond power and control: Towards an understanding of partner abusive men. Journal of Comparative Family Studies, 34(1), 7-22. https://doi.org/10.3138/jcfs.34.1.7

Ruddle, A., Pina, A., \& Vasquez, E. (2017). Domestic violence offending behaviors: A review of the literature examining childhood exposure, implicit theories, trait aggression and anger rumination as predictive factors. Aggression and Violent Behavior, 34, 154-165. https://doi.org/10.1016/j.avb.2017.01.016

Saunders, D. G. (2008). Group interventions for men who batter: A summary of program descriptions and research. Violence and Victims, 23(2), 156-172. https://doi.org/10.1891/0886-6708.23.2.156

Schauss, E., Zettler, H. R., \& Russell, A. (2019). Examining ACTV: An argument for implementing neuroscience-based and trauma-informed treatment models in offender treatment programs. Aggression and Violent Behavior, 46, 1-7. https://doi.org/10.1016/j.avb.2019.01.002

Spielberger, C. D. (1999). State-Trait Anger Expression Inventory-2. Psychological Assessment Resources.

Stover, C. S., Meadows, A. L., \& Kaufman, J. (2009). Interventions for intimate partner violence: Review and implications for evidence-based practice. Professional Psychology Research and Practice, 40(3), 223-233. https://doi.org/10.1037/a0012718

Swopes, R. M., Simonet, D. V., Jaffe, A. E., Tett, R. P., \& Davis, J. L. (2013). Adverse childhood experiences, posttraumatic stress disorder symptoms, and emotional intelligence in partner aggression. Violence and Victims, 28(3), 513-530. https://doi.org/10.1891/0886-6708.vv-d-12-00026

Teva, I., Hidalgo-Ruzzante, N., Perez-Garcia, M., \& Bueso-Izquierdo, N. (2020). Characteristics of childhood family violence experiences in Spanish batterers. Journal of interpersonal violence, 1-24. https://doi.org/10.1177/0886260519898436

Vitoria-Estruch, S., Romero-Martinez, A., Lila, M., \& Moya-Albiol, L. (2018). Differential cognitive profiles of intimate partner violence perpetrators based on alcohol consumption. Alcohol, 70, 61-71. https://doi.org/10.1016/j.alcohol.2018.01.006

Voith, L. A., Logan-Greene, P., Strodthoff, T., \& Bender, A. E. (2020). A paradigm shift in batterer intervention programming: A need to address unresolved trauma. Trauma, Violence \& Abuse, 21(4), 691-705. https://doi.org/10.1177/1524838018791268

Voith, L. A., Topitzes, J., \& Berg, K. A. (2020). The transmission of violence and trauma across development and environmental contexts: Intimate partner violence from the perspective of men with histories of perpetration. Child Abuse \& Neglect, 99, 104267. https://doi.org/10.1016/j.chiabu.2019.104267 
Waltz, J., Babcock, J. C., Jacobson, N. S., \& Gottman, J. M. (2000). Testing a typology of batterers. Journal of Consulting and Clinical Psychology, 68(4), 658-669. https://doi.org/10.1037/0022-006x.68.4.658

Wareham, J., Boots, D. P., \& Chavez, J. M. (2009). A test of social learning and intergenerational transmission among batterers. Journal of Criminal Justice, 37(2), 163-173. https://doi.org/10.1016/j.jcrimjus.2009.02.011

White, R. J., \& Gondolf, E. W. (2000). Implications of personality profiles for batterer treatment. Journal of Interpersonal Violence, 15(5), 467-488. https://doi.org/10.1177/088626000015005002 


\section{Table 1}

Socio-Demographic Characteristics of the Sample

\begin{tabular}{|c|c|c|c|c|c|c|}
\hline & $\begin{array}{c}\text { Total } \\
N=1008\end{array}$ & $\begin{array}{c}\text { With CFV } \\
n=339\end{array}$ & $\begin{array}{c}\text { Without CFV } \\
n=669\end{array}$ & & & \\
\hline & Mean $(S D)$ & Mean $(S D)$ & Mean $(S D)$ & $d$ & $t(d f)$ & $p$ \\
\hline Age & $37.40(10.43)$ & $37.63(10.80)$ & $37.28(10.25)$ & 0.03 & $0.51(1006)$ & .610 \\
\hline \multirow{2}{*}{$\begin{array}{l}\text { Length of relationship } \\
\text { with the victim (years) }\end{array}$} & $8.56(8.40)$ & $9.46(9.02)$ & $8.11(8.04)$ & 0.16 & $2.42(1006)$ & .016 \\
\hline & $N \quad(\%)$ & $\begin{array}{ll}n & (\%) \\
\end{array}$ & $\begin{array}{ll}n & (\%) \\
\end{array}$ & Phi & $\chi^{2}(d f)$ & $p$ \\
\hline \multicolumn{7}{|l|}{ Nationality } \\
\hline Spanish & $500(49.6 \%)$ & $159(46.9 \%)$ & $341(51 \%)$ & 0.04 & $1.49(1)$ & .222 \\
\hline Immigrant & $508(50.4 \%)$ & $180(53.1 \%)$ & $328(49 \%)$ & & & \\
\hline \multicolumn{7}{|l|}{ Education level } \\
\hline Primary & $532(52.8 \%)$ & $221(65.2 \%)$ & $311(46.5 \%)$ & & & \\
\hline Secondary & $425(42.1 \%)$ & $106(31.3 \%)$ & $319(47.7 \%)$ & 0.18 & $36.93(2)$ & .000 \\
\hline University & $51(5.1 \%)$ & $12(3.5 \%)$ & $39(5.8 \%)$ & & & \\
\hline \multicolumn{7}{|l|}{ Employment status } \\
\hline Employed & $548(54.3 \%)$ & $174(51.3 \%)$ & $374(55.9 \%)$ & & & \\
\hline Unemployed & $420(41.7 \%)$ & $147(43.4 \%)$ & $273(40.8 \%)$ & 0.06 & $3.54(2)$ & .171 \\
\hline Retired & $40(4 \%)$ & $18(5.3 \%)$ & $22(3.3 \%)$ & & & \\
\hline \multicolumn{7}{|l|}{ Children in common } \\
\hline Yes & $581(57.6 \%)$ & $210(61.9 \%)$ & $371(55.5 \%)$ & 0.06 & $3.88(1)$ & .049 \\
\hline No & $427(42.4 \%)$ & $129(38.1 \%)$ & $298(44.5 \%)$ & & & \\
\hline \multicolumn{7}{|l|}{$\begin{array}{l}\text { Previous psychiatric } \\
\text { history }\end{array}$} \\
\hline Yes & $569(56.4 \%)$ & $211(62.2 \%)$ & $358(53.5 \%)$ & 0.08 & $6.97(1)$ & .008 \\
\hline No & $439(43.6 \%)$ & $128(37.8 \%)$ & $311(46.5 \%)$ & & & \\
\hline \multicolumn{7}{|l|}{$\begin{array}{l}\text { Type of psychiatric } \\
\text { history }(n=569)\end{array}$} \\
\hline Addiction & $413(72.6 \%)$ & $151(71.6 \%)$ & $262(73.2 \%)$ & & & \\
\hline Emotional disorder & $119(20.9 \%)$ & $42(19.9 \%)$ & $77(21.5 \%)$ & 0.06 & $2.33(2)$ & .312 \\
\hline Personality disorder & $37(6.5 \%)$ & $18(8.5 \%)$ & $19(5.3 \%)$ & & & \\
\hline \multicolumn{7}{|l|}{ Programme access } \\
\hline Court-referred & $701(69.6 \%)$ & $228(67.3 \%)$ & $473(70.7 \%)$ & & & \\
\hline Prison & $227(22.5 \%)$ & $72(21.2 \%)$ & $155(23.2 \%)$ & 0.09 & $8.95(2)$ & .011 \\
\hline Voluntary & $80(7.9 \%)$ & $39(11.5 \%)$ & $41(6.1 \%)$ & & & \\
\hline
\end{tabular}

Note. In Spain, Primary studies (3-12 years old) and Secondary studies (12-18 years old). 


\section{Table 2}

Rates of Retention, Success, Improvement and Failure

\begin{tabular}{|c|c|c|c|c|c|c|c|c|c|}
\hline \multirow[t]{2}{*}{ Retention } & \multicolumn{2}{|c|}{$\begin{array}{c}\text { Total } \\
N=1008 \\
\end{array}$} & \multicolumn{2}{|c|}{$\begin{array}{l}\text { With CFV } \\
(n=339)\end{array}$} & \multicolumn{2}{|c|}{$\begin{array}{c}\text { Without CFV } \\
(n=669)\end{array}$} & \multirow[b]{2}{*}{ Phi } & \multirow[b]{2}{*}{$\chi^{2}(d f)$} & \multirow[b]{2}{*}{$p$} \\
\hline & $N$ & $(\%)$ & $n$ & $(\%)$ & $n$ & (\%) & & & \\
\hline Pre-treatment & 1008 & $(100 \%)$ & 339 & $(100 \%)$ & 669 & $(100 \%)$ & 0.06 & $3.53(1)$ & .060 \\
\hline 1-year follow-up & 801 & $(79.4 \%)$ & 258 & $(76.1 \%)$ & 543 & $(81.1 \%)$ & & & \\
\hline \multirow[t]{2}{*}{$\begin{array}{l}\text { Programme results } \\
\text { (1-year follow-up) }\end{array}$} & \multicolumn{2}{|c|}{$\begin{array}{c}\text { Total } \\
N=801\end{array}$} & \multicolumn{2}{|c|}{$\begin{array}{l}\text { With CFV } \\
(n=258)\end{array}$} & \multicolumn{2}{|c|}{$\begin{array}{l}\text { Without CFV } \\
(n=543)\end{array}$} & & & \\
\hline & $N$ & $(\%)$ & $n$ & $(\%)$ & $n$ & $(\%)$ & Phi & $\chi^{2}(d f)$ & $p$ \\
\hline Success & 290 & $(36.2 \%)$ & 107 & $(41.5 \%)$ & 183 & $(33.7 \%)$ & & & \\
\hline Improvement & 411 & $(51.3 \%)$ & 124 & $(48.1 \%)$ & 287 & $(52.9 \%)$ & 0.08 & $4.94(1)$ & .084 \\
\hline Failure & 100 & $(12.5 \%)$ & 27 & $(10.5 \%)$ & 73 & $(13.4 \%)$ & & & \\
\hline
\end{tabular}




\section{Table 3}

Results of Psychopathological Variables

\begin{tabular}{|c|c|c|c|c|c|c|c|}
\hline & Total & With CFV & Without CFV & \multirow[b]{2}{*}{$d$} & \multirow[b]{2}{*}{$t$} & \multirow[b]{2}{*}{$d f$} & \multirow[b]{2}{*}{$p$} \\
\hline & $M \quad(S D)$ & $M \quad(S D)$ & $M \quad(S D)$ & & & & \\
\hline \multicolumn{8}{|c|}{ SCL-90-R - GSI } \\
\hline Pre-treatment & $0.55(0.51)$ & $0.64(0.52)$ & $0.50(0.50)$ & 0.27 & 4.11 & 1006 & .000 \\
\hline Post-treatment & $0.39(0.41)$ & $0.44(0.46)$ & $0.36(0.39)$ & 0.21 & 2.67 & 471 & .008 \\
\hline Follow-up & $0.33(0.41)$ & $0.37(0.42)$ & $0.32(0.40)$ & 0.12 & 1.54 & 799 & .124 \\
\hline \multicolumn{8}{|c|}{ SCL-90-R - PSDI } \\
\hline Pre-treatment & $1.55(0.57)$ & $1.64(0.57)$ & $1.51(0.56)$ & 0.23 & 3.44 & 1006 & .001 \\
\hline Post-treatment & $1.33(0.46)$ & $1.35(0.41)$ & $1.32(0.48)$ & 0.06 & 0.86 & 858 & .388 \\
\hline Follow-up & $1.28(0.54)$ & $1.31(0.48)$ & $1.26(0.57)$ & 0.08 & 1.04 & 799 & .296 \\
\hline \multicolumn{8}{|c|}{ SCL-90-R - PST } \\
\hline Pre-treatment & $28.37(19.71)$ & $32.49(20.00)$ & $26.28(19.25)$ & 0.32 & 4.78 & 1006 & .000 \\
\hline Post-treatment & $22.87(18.62)$ & 26.05 (19.97) & $21.38(17.77)$ & 0.25 & 3.45 & 858 & .001 \\
\hline Follow-up & $19.41(18.51)$ & $21.68(19.95)$ & $18.33(17.70)$ & 0.18 & 2.40 & 799 & .017 \\
\hline \multicolumn{8}{|c|}{ SCL-90-R - Somatisation } \\
\hline Pre-treatment & $0.52(0.59)$ & $0.61(0.61)$ & $0.48(0.57)$ & 0.22 & 3.29 & 1006 & .001 \\
\hline Post-treatment & $0.41(0.53)$ & $0.45(0.56)$ & $0.39(0.51)$ & 0.11 & 1.45 & 858 & .146 \\
\hline Follow-up & $0.37(0.52)$ & $0.42(0.56)$ & $0.35(0.50)$ & 0.12 & 1.63 & 799 & .103 \\
\hline \multicolumn{8}{|c|}{ SCL-90-R - Obsessive-compulsive } \\
\hline Pre-treatment & $0.66(0.63)$ & $0.75(0.63)$ & $0.61(0.62)$ & 0.23 & 3.49 & 1006 & .000 \\
\hline Post-treatment & $0.49(0.52)$ & $0.52(0.57)$ & $0.47(0.50)$ & 0.11 & 1.49 & 858 & .138 \\
\hline Follow-up & $0.41(0.51)$ & $0.42(0.51)$ & $0.40(0.51)$ & 0.04 & 0.53 & 799 & .593 \\
\hline \multicolumn{8}{|c|}{ SCL-90-R - Interpersonal sensitivity } \\
\hline Pre-treatment & $0.51(0.59)$ & $0.59(0.61)$ & $0.46(0.57)$ & 0.22 & 3.38 & 1006 & .001 \\
\hline Post-treatment & $0.36(0.47)$ & $0.44(0.52)$ & $0.32(0.44)$ & 0.26 & 3.39 & 464.96 & .001 \\
\hline Follow-up & $0.30(0.46)$ & $0.35(0.49)$ & $0.28(0.44)$ & 0.16 & 2.10 & 799 & .036 \\
\hline \multicolumn{8}{|c|}{ SCL-90-R - Depression } \\
\hline Pre-treatment & $0.81(0.74)$ & $0.91(0.77)$ & $0.75(0.71)$ & 0.21 & 3.14 & 1006 & .002 \\
\hline Post-treatment & $0.54(0.57)$ & $0.62(0.62)$ & $0.51(0.54)$ & 0.19 & 2.58 & 858 & .010 \\
\hline Follow-up & $0.46(0.61)$ & $0.51(0.73)$ & $0.43(0.55)$ & 0.13 & 1.70 & 799 & .089 \\
\hline \multicolumn{8}{|c|}{ SCL-90-R - Anxiety } \\
\hline Pre-treatment & $0.48(0.59)$ & $0.57(0.58)$ & $0.43(0.58)$ & 0.24 & 3.56 & 1006 & .000 \\
\hline Post-treatment & $0.33(0.45)$ & $0.39(0.49)$ & $0.30(0.43)$ & 0.20 & 2.61 & 471.76 & .009 \\
\hline Follow-up & $0.27(0.45)$ & $0.31(0.48)$ & $0.26(0.44)$ & 0.11 & 1.49 & 799 & .137 \\
\hline \multicolumn{8}{|c|}{ SCL-90-R - Hostility } \\
\hline Pre-treatment & $0.34(0.55)$ & $0.42(0.59)$ & $0.30(0.53)$ & 0.23 & 3.31 & 1006 & .001 \\
\hline Post-treatment & $0.23(0.42)$ & $0.27(0.42)$ & $0.21(0.42)$ & 0.15 & 1.99 & 858 & .047 \\
\hline Follow-up & $0.18(0.40)$ & $0.20(0.38)$ & $0.17(0.41)$ & 0.07 & 0.95 & 799 & .340 \\
\hline \multicolumn{8}{|c|}{ SCL-90-R - Phobic anxiety } \\
\hline Pre-treatment & $0.25(0.43)$ & $0.31(0.45)$ & $0.23(0.42)$ & 0.18 & 2.72 & 1006 & .007 \\
\hline Post-treatment & $0.18(0.37)$ & $0.21(0.35)$ & $0.17(0.37)$ & 0.12 & 1.67 & 858 & .095 \\
\hline Follow-up & $0.16(0.35)$ & $0.17(0.33)$ & $0.15(0.36)$ & 0.06 & 0.79 & 799 & .429 \\
\hline \multicolumn{8}{|c|}{ SCL-90-R - Paranoid ideation } \\
\hline Pre-treatment & $0.65(0.66)$ & $0.77(0.68)$ & $0.59(0.64)$ & 0.27 & 4.02 & 1006 & .000 \\
\hline Post-treatment & $0.48(0.57)$ & $0.58(0.60)$ & $0.44(0.55)$ & 0.25 & 3.29 & 495.9 & .001 \\
\hline Follow-up & $0.40(0.51)$ & $0.46(0.54)$ & $0.37(0.50)$ & 0.16 & 2.06 & 466.37 & .040 \\
\hline SCL-90-R - Ps & & & & & & & \\
\hline Pre-treatment & $0.36(0.48)$ & $0.44(0.51)$ & $0.31(0.46)$ & 0.26 & 3.82 & 1006 & .000 \\
\hline Post-treatment & $0.23(0.38)$ & $0.29(0.42)$ & $0.20(0.35)$ & 0.21 & 2.75 & 461.55 & .006 \\
\hline Follow-up & $0.20(0.36)$ & $0.25(0.40)$ & $0.18(0.34)$ & 0.19 & 2.37 & 433.49 & .018 \\
\hline STAXI-2 - An & & & & & & & \\
\hline Pre-treatment & $22.24(11.75)$ & $23.50(12.16)$ & $21.60(11.49)$ & 0.16 & 2.44 & 1006 & .015 \\
\hline Post-treatment & $18.06(10.72)$ & $17.78(10.77)$ & $18.19(10.70)$ & 0.04 & 0.52 & 858 & .606 \\
\hline
\end{tabular}

Fernández-Montalvo, J., Echauri, J.A., Siria, S., López-Goñi, J.J., Azcárate, J.M. y Martínez, M. (in press). Is Psychological Treatment Equally Effective for Intimate Partner Violence Perpetrators with and without Childhood Family Violence? Legal and Criminological

Psychology. https://doi.org/10.1111/lcrp.12187 
Follow-up $17.60(10.88) \quad 17.40(11.06) \quad 17.69(10.80) \quad 0.03 \quad 0.35$

Note. Pre-treatment: Total sample $(N=1008)$, with CFV $(n=339)$, without CFV $(n=669)$.

Post-treatment: Total sample $(N=860)$, with CFV $(n=275)$, without CFV $(n=585)$.

Follow-up: Total sample $(N=801)$, with $\mathrm{CFV}(n=258)$, without CFV $(n=543)$. 


\section{Table 4}

Treatment Progression in both Groups

\begin{tabular}{|c|c|c|c|c|c|c|c|c|}
\hline & \multirow[b]{2}{*}{ Group } & \multirow[b]{2}{*}{$\boldsymbol{F}$} & \multicolumn{2}{|c|}{ Pre-Post } & \multicolumn{2}{|c|}{ Pre-Follow } & \multicolumn{2}{|c|}{ Post-Follow } \\
\hline & & & $t$ & $p$ & $t$ & $p$ & $t$ & $p$ \\
\hline \multirow{2}{*}{ GSI } & With CFV & $59.9 *$ & 7.70 & .000 & 9.34 & .000 & 3.89 & .000 \\
\hline & Without CFV & $54.7 *$ & 7.26 & .000 & 8.66 & .000 & 3.13 & .002 \\
\hline \multirow{2}{*}{ PST } & With CFV & $55.1^{*}$ & 6.59 & .000 & 9.12 & .000 & 5.01 & .000 \\
\hline & Without CFV & $63.3^{*}$ & 6.43 & .000 & 9.72 & .000 & 5.87 & .000 \\
\hline \multirow{2}{*}{ PSDI } & With CFV & $51.3^{*}$ & 8.36 & .000 & 8.20 & .000 & 1.78 & .076 \\
\hline & Without CFV & $46.6^{*}$ & 7.05 & .000 & 8.49 & .000 & 2.59 & .010 \\
\hline \multirow{2}{*}{ Somatization } & With CFV & $18.6^{*}$ & 4.85 & .000 & 5.23 & .000 & 1.35 & .179 \\
\hline & Without CFV & $24.7 *$ & 4.64 & .000 & 6.16 & .000 & 2.20 & .028 \\
\hline \multirow{2}{*}{ Obsessive-compulsive } & With CFV & $56.1^{*}$ & 7.20 & .000 & 9.06 & .000 & 4.10 & .000 \\
\hline & Without CFV & $37.2 *$ & 5.37 & .000 & 7.26 & .000 & 3.86 & .000 \\
\hline \multirow{2}{*}{ Interpersonal sensitivity } & With CFV & $29.8^{*}$ & 5.02 & .000 & 6.76 & .000 & 3.02 & .003 \\
\hline & Without CFV & $37.3 *$ & 5.90 & .000 & 7.48 & .000 & 2.24 & .026 \\
\hline \multirow{2}{*}{ Depression } & With CFV & $35.5^{*}$ & 7.10 & .000 & 6.97 & .000 & 2.28 & .023 \\
\hline & Without CFV & $74.2 *$ & 8.36 & .000 & 10.37 & .000 & 4.17 & .000 \\
\hline \multirow{2}{*}{ Anxiety } & With CFV & $34.7 *$ & 5.44 & .000 & 7.32 & .000 & 3.50 & .001 \\
\hline & Without CFV & $36.3^{*}$ & 5.59 & .000 & 7.29 & .000 & 2.88 & .004 \\
\hline \multirow{2}{*}{ Hostility } & With CFV & $22.9^{*}$ & 4.25 & .000 & 5.74 & .000 & 3.13 & .002 \\
\hline & Without CFV & $13.8^{*}$ & 3.12 & .002 & 4.60 & .000 & 2.34 & .020 \\
\hline \multirow{2}{*}{ Phobic anxiety } & With CFV & $16.9^{*}$ & 4.00 & .000 & 5.42 & .000 & 2.04 & .042 \\
\hline & Without CFV & $10.4^{*}$ & 3.23 & .001 & 4.12 & .000 & 1.41 & .159 \\
\hline \multirow{2}{*}{ Paranoid ideation } & With CFV & $42.1^{*}$ & 5.38 & .000 & 8.79 & .000 & 3.95 & .000 \\
\hline & Without CFV & $39.9 *$ & 6.08 & .000 & 7.70 & .000 & 2.97 & .003 \\
\hline \multirow{2}{*}{ Psychoticism } & With CFV & $24.0^{*}$ & 4.98 & .000 & 5.98 & .000 & 1.82 & .069 \\
\hline & Without CFV & $31.4^{*}$ & 5.49 & .000 & 6.66 & .000 & 1.84 & .067 \\
\hline \multirow{2}{*}{ Anger Expression Index } & With CFV & $39.3^{*}$ & 6.76 & .000 & 7.12 & .000 & 0.72 & .474 \\
\hline & Without CFV & $32.1^{*}$ & 6.05 & .000 & 7.09 & .000 & 1.10 & .274 \\
\hline
\end{tabular}

Note. ${ }^{*} p<.001$ 


\section{Figure 1}

Participants' Flow Diagram

\section{Enrolment}

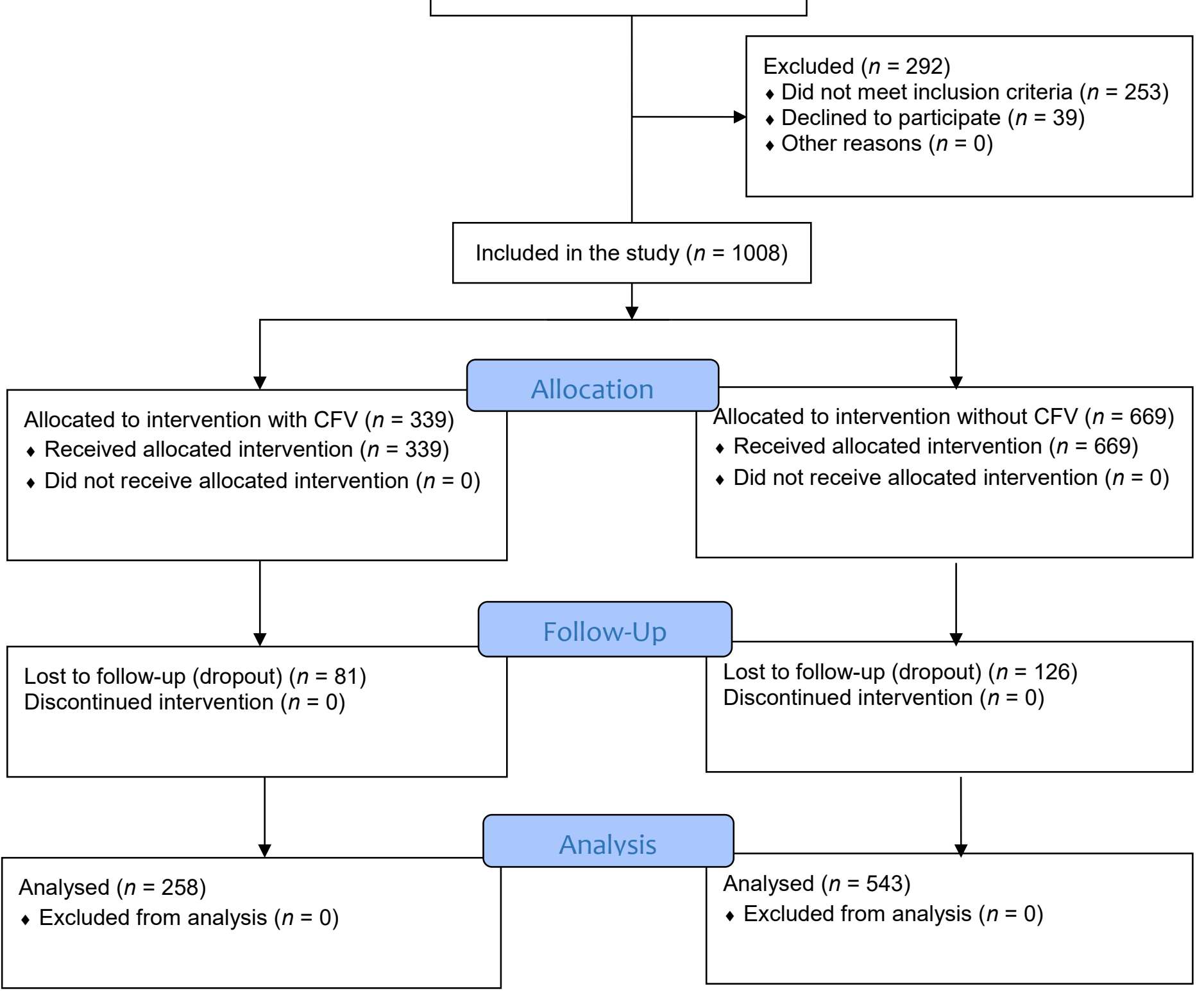

Fernández-Montalvo, J., Echauri, J.A., Siria, S., López-Goñi, J.J., Azcárate, J.M. y Martínez, M. (in press). Is Psychological Treatment Equally Effective for Intimate Partner Violence Perpetrators with and without Childhood Family Violence? Legal and Criminological

Psychology. https://doi.org/10.1111//crp.12187 